American Journal of Applied Sciences 4 (12): 1079-1083, 2007

ISSN 1546-9239

(C) 2007 Science Publications

\title{
Simulation Model of Brushless Excitation System
}

\author{
Ahmed N. Abd Alla \\ College of Electric and Electronics Engineering, \\ Huazhong University of Science and Technology, Wuhan430074, China
}

\begin{abstract}
Excitation system is key element in the dynamic performance of electric power systems, accurate excitation models are of great importance in simulating and investigating the power system transient phenomena. Parameter identification of the Brushless excitation system was presented. First a block diagram for the EXS parameter was proposed based on the documents and maps in the power station. To identify the parameters of this model, a test procedure to obtain step response, was presented. Using the Genetic Algorithm with the Matlab-software it was possible to identify all the necessary parameters of the model. Using the same measured input signals the response from the standard model showed nearly the same behavior as the excitation system.
\end{abstract}

Key words: Excitation system, parameter estimation, genetic algorithm method, model validation

\section{INTRODUCTION}

Power system small signal, transient and dynamic stability studies are only as accurate as the underlying models used in the computer analysis. The validity of the results of these studies depends heavily on the accuracy of the model parameters of the system components. In practice, the parameters commonly used in stability studies are manufacturer specified values, or "typical" values. These typical values may be grossly inaccurate, as various parameters may drift over time or with operating condition. Thus, to avoid such problems and to obtain more realistic simulation results, the identification of the system parameters on based field test is recommended.

Several attempts have been made to obtain EXS models from field tests. A second order static excitation system has been discussed in $^{[1]}$. $\mathrm{In}^{[2]}$ generalized least square approach is used to model an excitation system. Parameter estimation of a pumped storage power plant using stochastic approaches is discussed $\mathrm{in}^{[3]}$. Identification of exciter constants using Prediction error Method (PEM) is addressed $\mathrm{in}^{[4]}$. $\mathrm{In}^{[5]}$, the necessity to represent the EXS in full and close to the practical implementations for accurate and reliable results has been addressed. The feasibility and necessity of a nonlinear structure for EXS is discussed in ${ }^{[6]}$.

In this study, the genetic algorithm is introduced into parameter identification of excitation system model. It is shown by Simulation results that the genetic algorithm-based model identification method is one applied method and satisfactory identification results can be got with it. It should be emphasized that this method is not model-dependent and therefore, it is readily applicable to a variety of model types and different test procedures.

System Description and the test procedure: The unit under study is a $400[\mathrm{MW}], 13[\mathrm{KV}]$ steam turbine generator set at the power plant and a Brushless EXS (IEEE ESAC2A type exciter mode) is used. A Brushless EXS is popular since it eliminates commentators, brushes and slip rings. It was developed to avoid problems with the use of brushes that were perceived to exist when supplying the high field current of very large generators.

All components in these systems are static or stationary. Static rectifiers, controlled or uncontrolled, supply the excitation current directly to the field of the main synchronous generator through slip rings. The supply of power to the rectifiers is from assistant exciter $^{[7]}$.

\section{System description}

1. Real power plant model: The power station provides the parameter of generator and the excitation system model as shown in Fig. 1.

2. Power plant with IEEE ESAC2A type exciter model: The proposed block diagram of the EXS is shown in Fig. 2. This block diagram has been proposed based on very extensive studies using the documents

Corresponding Author: Ahmed N. Abd Alla, College of Electric and Electronics Engineering ,Huazhong University of Science and Technology, Wuhan430074, China 


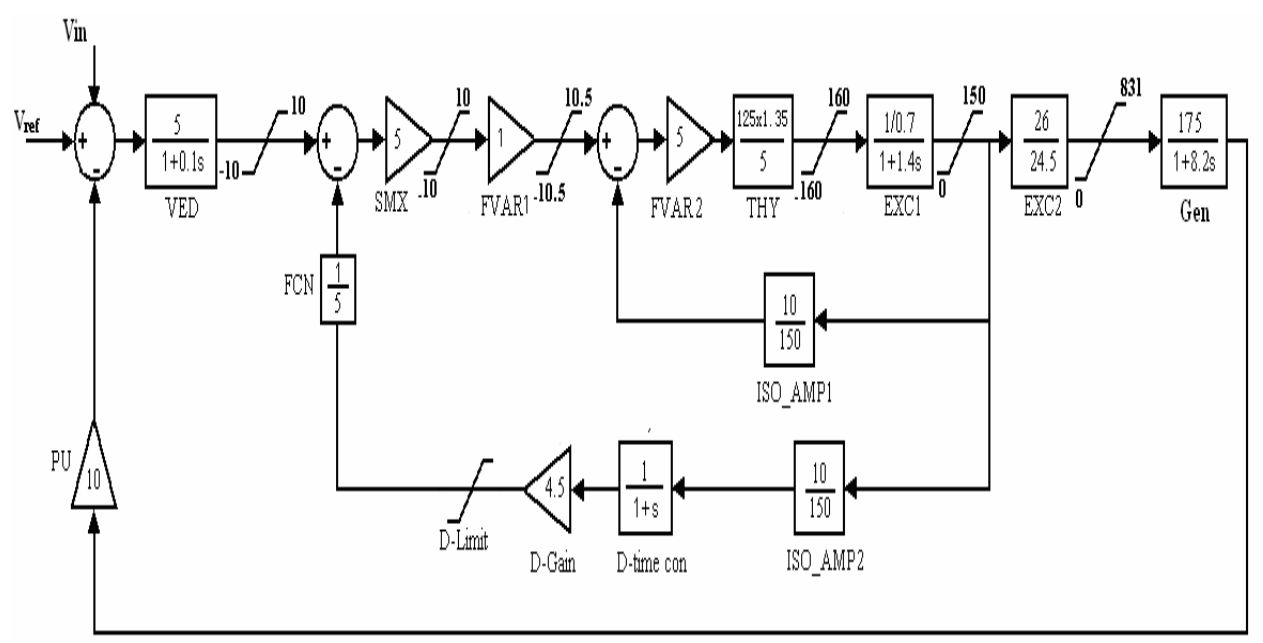

Fig. 1: Block diagram of steam power plant model

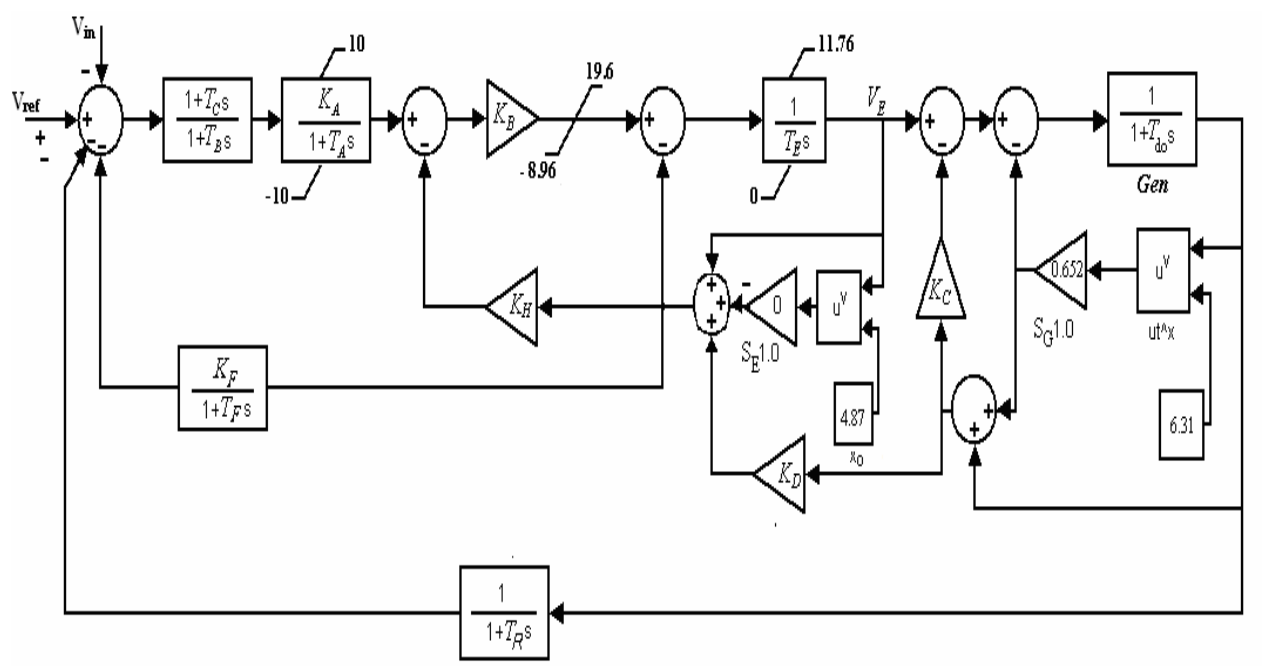

Fig. 2: Block diagram of Houshi power plant model with IEEE ESAC2A type exciter model

and circuit diagrams in the power station. Details of such studies are not described here for the sake of brevity.

This model a high initial response field controlled alternator-rectifier excitation system in which the alternator main exciter is used with noncontrolled rectifier. These models are applicable for simulating the performance of Westinghouse high initial response brushless excitation systems ${ }^{[8]}$.

A direct negative feedback, $\mathrm{V}_{\mathrm{H}}$, around the exciter field time constant reduces its effective value and thereby increases the bandwidth of the excitation system small signal response. The time constant is reduced by the gain $\left(1+\mathrm{K}_{\mathrm{B}} \mathrm{K}_{\mathrm{H}}\right)$ of the compensation loop and is normally more than an order of magnitude lower than the time constant without compensation. To obtain high initial response with this system, a very high forcing voltage, $\mathrm{V}_{\mathrm{RMAX}}$, is applied to the exciter field.

A limiter sensing exciter field current allows high forcing, but limits the current. By limiting the exciter field current, exciter output voltage, $\mathrm{V}_{\mathrm{E}}$, is limited to a selected value, $\mathrm{V}_{\mathrm{LR}}$, which is usually determined by the specified excitation system response ratio. The output signals from the voltage regulator, $\mathrm{V}_{\mathrm{A}}$ and time constant compensation, $\mathrm{V}_{\mathrm{H}}$, elements are compared with the output signal, $\mathrm{V}_{\mathrm{L}}$, from the limiter in control logic circuitry, which functions to provide a sharp transition from regulator control to limiter control of excitation at the limit point. Excitation is controlled by the more negative of the two control signals. 
Although the current limit is realized physically, the time constants associated with the loop can be extremely small. Therefore, the limit can be modeled as a positive limit on exciter voltage back of commutating reactance.

In this type of system, $\mathrm{T}_{\mathrm{A}}, \mathrm{T}_{\mathrm{C}}$ and $\mathrm{T}_{\mathrm{B}}$ represent Automatic Voltage Regulator's (AVR) time constants, $\mathrm{K}_{\mathrm{A}}$ represents $\mathrm{AVR}$ gain $. \mathrm{T}_{\mathrm{E}}, \mathrm{K}_{\mathrm{E}}$ and $\mathrm{S}_{\mathrm{E}}$ represent the exciter.

Test procedure: The first step in the testing process is to prepare a test procedure. This requires a review of the information on the controls from the instruction manuals and block diagrams supplied by the manufacturer. A review of any plant specific concerns should also be made, for example, any operating restrictions imposed on the plant. This allows the test procedure to be adapted to the specific requirements exhibited by the plant.

In the defined test procedure of the EXS was treated as a single input single output. In this subsystems, $\mathrm{u}(\mathrm{kT})$ and $\mathrm{v}(\mathrm{kT})$ are the samples of the system input and output with constant sampling period $\mathrm{T}$. The overall input signal $\mathrm{V}_{\text {in }}$ (input voltage for identification) was considered to be applied to the summing point of $\mathrm{V}_{\text {ref }}$.

The controller of excitation system is supplied by $+10 \%$ step signal in sum input point of the excitation controller, this signals used to identify system parameter. Another tests were performed by different step signals $(5 \%,-5 \%, 2 \%$ and $-2 \%$ step signal), this signals used to verify system parameter and Generator terminal Voltage.

Excitation system parameter identification: The proposed identification procedure is a simulation based process that uses a genetic algorithm as optimization tool $^{[9]}$. The simulation model of the system is excited by the same input. The output of the system, which is the set of available measurements, is compared to the simulated output of the model. The error between the two outputs is used as input to a genetic algorithm optimization module, which updates the model parameters in such a way that this error is minimized.

The object function used to identify transfer function of excitation system can be calculated as:

$\mathrm{Q}=\Sigma\left(\mathrm{y}-\mathrm{y}_{\mathrm{o}}\right)^{2}$

Where, $\mathrm{y}$ is the output of identification result, $\mathrm{y}_{\mathrm{o}}$ is the output of actual process.

The transfer function of excitation system can be described as shown in Fig. 1:

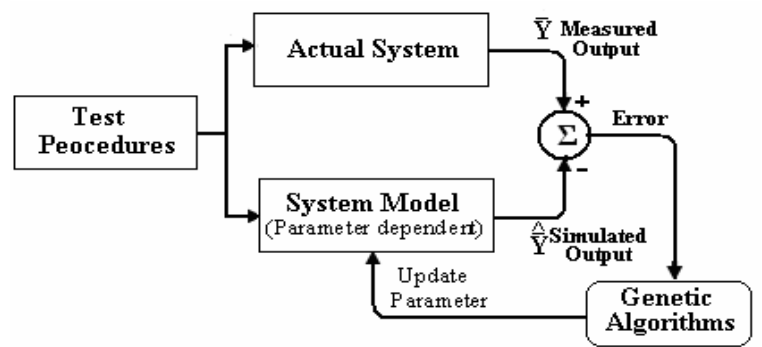

Fig. 3: Block diagram of identification procedure

The optimization process is to get the optimal parameters $\mathrm{T}_{\mathrm{C}}, \mathrm{T}_{\mathrm{B}}, \mathrm{T}_{\mathrm{F}}, \mathrm{K}_{\mathrm{F}}, \mathrm{K}_{\mathrm{A}}, \mathrm{T}_{\mathrm{A}}, \mathrm{T}_{\mathrm{R}}, \mathrm{K}_{\mathrm{H}}, \mathrm{K}_{\mathrm{E}}, \mathrm{K}_{\mathrm{D}}, \mathrm{T}_{\mathrm{do}}$ which can make $\mathrm{Q}$ minimum.

where, the searching area of the coefficients can be set according to experience, $\mathrm{T}_{\mathrm{R}}, \mathrm{T}_{\mathrm{B}}$ and $\mathrm{T}_{\mathrm{C}}=0 \sim 0.2, \mathrm{~T}_{\mathrm{F}}$ and $\mathrm{T}_{\mathrm{E}}=0.5 \sim 2.5, \mathrm{~K}_{\mathrm{A}}=150 \sim 300, \mathrm{~K}_{\mathrm{D}}$ and $\mathrm{K}_{\mathrm{H}}=0.1 \sim 0.3$, $\mathrm{K}_{\mathrm{B}}=1 \sim 3$ and $\mathrm{K}_{\mathrm{C}}$ and $\mathrm{K}_{\mathrm{F}}=0.01 \sim 0.03, \mathrm{~T}_{\mathrm{do}}=9 \sim 10$.

A key feature of the approach is that the estimation process is not model-specific and it is therefore straight forward to switch between large varieties of models.

\section{SIMULATION RESULTS}

Here, we suppose to have the data obtained from the field test and estimation the parameters in Fig. 2 by using genetic algorithm.

Parameter identification of the excitation system model: The genetic algorithm identification method described earlier is applied to the EXS at no-load operating conditions by $10 \%$ step signal as shown in Fig. $4^{[9]}$.

Model validation: In any identification procedure, model validation is the most important step. The easiest way to validate a model is to compare the simulated model response to the measured output to the same input. This strategy was selected here for model validation $^{[10,11]}$.

Figure 5 compare the output result of the terminal voltage response of real power plant model and power with IEEE ESAC2A type exciter model.

As the figures show the power plant with IEEE ESAC2A type exciter model are good enough to represent the system. All the simulation results also show the superiority of this model over the real improved power plant model. Since the superiority of this model is not quite clear from the figures, Table 2 compares the error margin for the two models. 
Am. J. Applied Sci., 4 (12): 1079-1083, 2007

Table 1: The excitation system parameter identification result

\begin{tabular}{lcll}
\hline $\mathrm{T}_{\mathrm{R}}$ & 0.006 & $\mathrm{~K}_{\mathrm{H}}$ & 0.29 \\
$\mathrm{~T}_{\mathrm{B}}$ & 0.0003 & $\mathrm{~K}_{\mathrm{F}}$ & 0.021 \\
$\mathrm{~T}_{\mathrm{C}}$ & 0.00001 & $\mathrm{~T}_{\mathrm{F}}$ & 1.12 \\
$\mathrm{~K}_{\mathrm{A}}$ & 280 & $\mathrm{~K}_{\mathrm{C}}$ & 0.05 \\
$\mathrm{~T}_{\mathrm{A}}$ & 0.07 & $\mathrm{~K}_{\mathrm{D}}$ & 0.12 \\
$\mathrm{~K}_{\mathrm{B}}$ & 2,51 & $\mathrm{~K}_{\mathrm{E}}$ & 1 \\
$\mathrm{~T}_{\mathrm{E}}$ & 2.01 & $\mathrm{~T}_{\mathrm{do}}$ & 9.2 \\
\hline
\end{tabular}

Table 2: Comparison between the two models responding to the 5\%

\begin{tabular}{|c|c|c|c|c|c|}
\hline \multirow[t]{2}{*}{$\begin{array}{l}\text { MODEL'S } \\
\text { Charact. }\end{array}$} & \multicolumn{2}{|l|}{$\begin{array}{l}\text { Model } \\
\text { (1) }\end{array}$} & \multicolumn{2}{|l|}{$\begin{array}{l}\text { Model } \\
\text { (2) }\end{array}$} & \multirow{2}{*}{$\begin{array}{l}\text { Tests } \\
\text { A. R. } \\
\text { A }\end{array}$} \\
\hline & S.R. & R.M. & S.R. & R.M. & \\
\hline $\mathrm{t}_{\mathrm{d}}|\mathrm{s}|$ & 0.061 & 0.038 & 0.093 & 0.006 & 0.099 \\
\hline $\mathrm{t}_{\mathrm{r}}|\mathrm{s}|$ & 0.400 & 0.068 & 0.362 & 0.030 & 0.332 \\
\hline $\mathrm{t}_{\mathrm{p}}|\mathrm{s}|$ & 0.895 & 0.302 & 0.615 & 0.022 & 0.593 \\
\hline $\mathrm{t}_{\mathrm{s}}|\mathrm{s}|$ & 2.287 & 1.042 & 1.980 & 0.735 & 1.245 \\
\hline $\operatorname{Mp}(\%$ & 8.196 & 38.633 & 31.083 & 15.745 & 46.829 \\
\hline V.R (\%) & 0.508 & - & 0.692 & - & 0.865 \\
\hline
\end{tabular}

Where: Model (1) =Real power plant model, Model (2)= Power plant with IEEE ESAC2A type exciter, $t_{d}=$ delay time, $t_{r}=$ rise time, $t_{p}$ =peak time, $t_{\mathrm{s}}=$ stable time, $\mathrm{Mp}=$ Max. peak, V.R.=Voltage Regulation, S.R= Simulation Result, R.M.= Error Margin , Actual Response $=$ A. R., Charact.$=$ Characteristic .

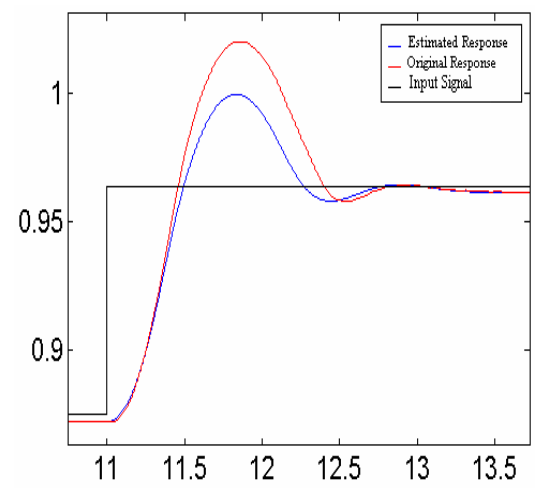

(a) Terminal voltage response

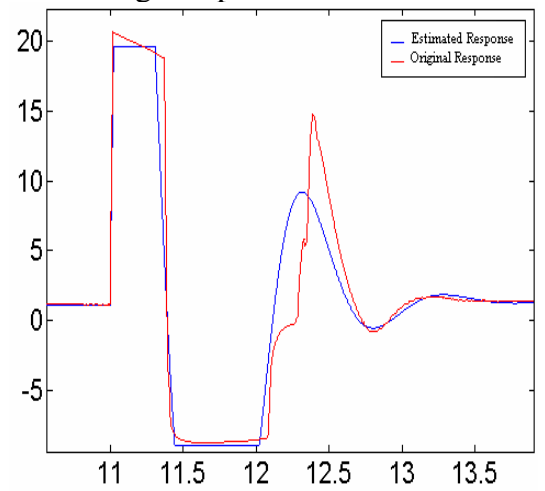

(b) Excitation voltage response

Fig. 4: Comparison under 10\% step signal

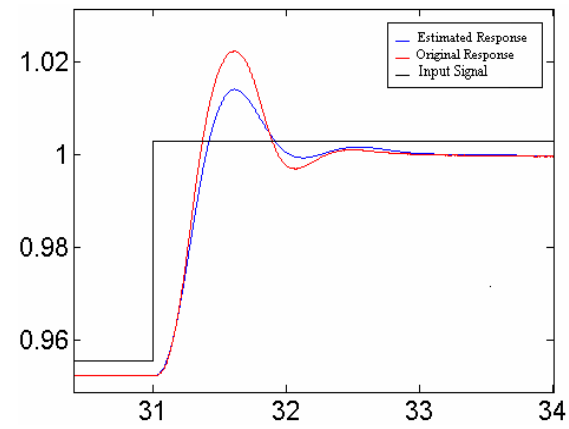

(a) Terminal voltage response

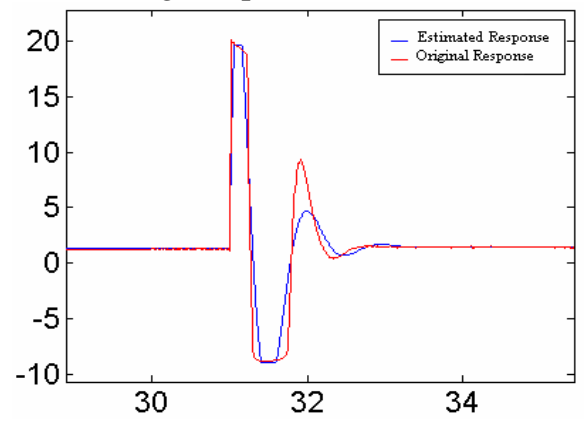

(b) Excitation Voltage Response

Fig. 5: Comparison under 5\% step signal

\section{CONCLUSION}

In this study, genetic algorithm for the identification of excitation system parameter model in steam power station. The main advantages of the proposed methodology are the few input data requirements, its flexibility and the simplicity of its mechanism. The obtained results successfully demonstrate the feasibility and practicality of the proposed GA approach.

\section{REFERENCES}

1. Rogers, G., 1992. Demystifying power system oscillations. IEEE Comput. Appl. Power, 9: 30-35.

2. Zazo, A., J.L. Zamora, L. Rouco and F.L. Pagola, 1994. Identification of excitation systems from time response tests. Proc. Contr. 94, Inst. Elect. Eng. Conf. Publication 389, pp: 839-843.

3. Guo, T.Y., C.S. Liu and C.T. Huang, 1993. Identification of excitation system model parameters via finalization field tests. Proc. Inst. Elect. Eng. 2nd Intl. Conf. Advances Power Syst. Contr., Oper. Manage., pp: 833-838.

4. Rasoli, M. and M. Karrari, 2002. Identification of brushless excitation system model parameters at different operting conditions via field tests. 14th PSCC, Sevilla, 24-28 June. 
5. Liaw, C.M., T.S. Liu, A.H. Liu, Y.T. Chen and C.J. Lin, 1992. Parameter estimation of excitation systems from sampled data. IEEE Trans. Automat. Contr., 37: 663-666.

6. Bhaskar, R., M.L. Crow, K. Erickson, K. Shah and R. Bhaskar, 1998. Excitation system nonlinear parameter estimation for power system stability studies: Feasibility study. Proc. 30th North Amer. Power Symp., pp: 453-458.

7. Ljung, L.,1987. System Identification, Theory for the User. Prentice Hall.

8. Dillman, T.L., J.W. Skoog Lund, F.W. Keay South and C. Raczkowsk, A High Initial Response Brushless Excitation System. IEE Trans.
9. Liang, L.C., L.J. Zhen, N. Yuguang and Y. Wangye, 2002. The application of genetic algorithm in model identification. Proc. IEEE TENCON'02, pp: 1261-1264.

10. IEEE Guide for Identification, Testing and Evaluation of the Dynamic Performance of Excitation Control Systems.

11. IEEE Recommended Practice for Excitation System Models for Power System Stability Studies, Aug. 1992. 